\title{
O marxismo nos departamentos de ciências econômicas no Brasil durante a ditadura militar *
}

\author{
Ian Coelho de Souza Almeida \\ Marco Antônio Ribas Cavalieri ${ }^{\text {**** }}$
}

\begin{abstract}
Resumo
Este artigo analisa as possíveis interferências do regime militar brasileiro (1964-1985) no ensino e pesquisa em economia marxista. Em primeiro lugar, examinamos grades curriculares, programas e bibliografias de departamentos de economia principalmente dos anos 1960 a 1970. Segundo, entrevistamos professores que lecionaram ou estudaram durante o período do regime militar. Não identificamos uma interferência sistemática e bem organizada sobre a economia marxista nos departamentos de economia. Entretanto, o clima de medo e desconfiança que reinou nas universidades brasileiras nessa época fez surgir o que podemos chamar de "autocensura".
\end{abstract}

Palavras-chave: Ditadura militar; Marxismo; História do pensamento econômico - Brasil; Liberdade acadêmica; Ensino e Pesquisa em Economia.

\begin{abstract}
Marxism in economics departments in Brazil during the military dictatorship

The paper analyzes the possible interferences of the Brazilian military regime (1964-1985) in teaching and research on Marxist economics. First, we examined courses, syllabi, and reading assignments from economics departments mainly from the 1960s and 1970s. Second, we interviewed professors that either studied or taught during the military regime years. We were unable to identify a systematic and well-organized interference in these departments that lead to constraining the teaching and research on Marxist economics; however, the climate of fear and suspicion that reigned in Brazilian universities led scholars to adopt what we could call "self-censorship".
\end{abstract}

Keywords: Military Dictatorship in Brazil; Marxism; History of Brazilian Economic Thought; Academic freedom; Economics' teaching and research.

JEL A10, B24, B29.

\section{Introdução}

O estudo aqui apresentado visou compreender as formas pelas quais o regime militar brasileiro afetou a ciência econômica universitária no país. Dentro disso, estivemos interessados, em especial, no estudo e pesquisa em teoria econômica marxista. Existe uma literatura importante a respeito das perseguições

*Artigo recebido em 18 de março de 2016 e aprovado em 25 de julho de 2017.

** Doutorando em Economia do Centro de Desenvolvimento e Planejamento Regional da Universidade Federal de Minas Gerais (Cedeplar/UFMG) / Bolsista Capes (Coordenação de Aperfeiçoamento de Pessoal de Nível Superior), Belo Horizonte, MG, Brasil. E-mail: iancsalmeida@gmail.com.

*** Professor Adjunto da Universidade Federal do Paraná, do Programa de Pós-Graduação em Desenvolvimento Econômico (PPGDE-UFPR), Curitiba, Paraná, Brasil. E-mail: cavaga@uol.com.br. 
políticas nas instituições de ensino, principalmente públicas, durante o período. Entretanto, o estudo com foco exclusivo na economia é bastante escasso, senão mesmo inexistente.

Para estudar esse período e o assunto, resolvemos utilizar duas metodologias que se complementam. Primeiro, examinamos uma série de registros acadêmicos de instituições de ensino que nos franquearam o acesso aos documentos. Essa documentação inclui grades curriculares, algumas ementas, outros poucos programas e até mesmo diários de classe. Nesses documentos, estudamos a presença de conteúdo com a exposição das ideias de Marx, de marxistas ou sobre o socialismo. A profundidade da informação que pudemos retirar desses documentos foi bastante variada, embora algumas conclusões iniciais sejam possíveis a partir do material.

A pesquisa nesse material de arquivo foi complementada por uma segunda fase baseada no método da história oral. Com isso, visamos principalmente completar as lacunas que a primeira parte do estudo deixara em aberto. Ademais, como a perseguição política carrega um alto grau de afetação psicológica em relação aos envolvidos, pensamos que esse aspecto, que consideramos importante, somente poderia sobressair com o uso das entrevistas. Assim, os depoimentos recolhidos são em sua maioria de economistas envolvidos nas décadas de 1960 e 1970 com o ensino e a pesquisa de inclinação marxista (fossem eles alunos ou professores). Porém, as entrevistas não se esgotam em entrevistados identificados com o marxismo. Para que pudéssemos obter impressões mais gerais, entrevistamos personagens como, por exemplo, o ex-ministro e articulador da modernização do ensino de pós-graduação em economia no país, Delfim Netto. Da mesma forma, Luiz Carlos Bresser-Pereira não é um economista ligado ao marxismo. Contudo, escolhemos entrevistá-lo porque ele poderia oferecer a perspectiva de um professor de instituição particular. Adicionalmente, gentilmente concordaram em nos conceder entrevistas os ilustres professores Antônio Plínio Pires de Moura, Claus Magno Germer, João Antônio de Paula, Luiz Gonzaga Belluzzo, Paul Israel Singer e Theotônio dos Santos.

Adiantando nosso resultado mais geral, devemos apontar que fomos capazes de averiguar a inexistência de uma interferência bem organizada e sistemática do regime militar sobre do ensino de economia. Entretanto, isso não elimina, é claro, a constatação de que o próprio ambiente de repressão, violência e censura funcionou como supressor dos estudos e ensino com inclinações marxistas. Isso ocorreu especialmente através do que a literatura sobre a ditadura chama de "autocensura".

\section{$1 \mathrm{O}$ novo regime e as universidades}

Do ponto de vista dos nossos objetivos, são duas as principais marcas da atuação dos governos militares sobre as instituições de ensino superior. 
A primeira é a reforma universitária levada a cabo nos últimos anos da década de 1960, objeto de disputas desde a década de 1940 (Cunha, 1988). Segundo Favero (2007, p. 34) e Klein e Schwartzman (1993), a reforma efetivamente realizada não representou grande ruptura com as propostas anteriores ao regime, inclusive, adotando algumas das sugestões anteriores, como a substituição do sistema de cátedras pelo de departamentos, a organização do fomento à pesquisa e à pós-graduação, a reestruturação da carreira docente, assim como o tripé ensino, pesquisa e extensão. Outro ponto importante da reforma foi a tentativa de findar a gratuidade do ensino superior público, algo que não se concretizou (Cunha, 2007, p. 333).

Em uma visão mais crítica, nas palavras do famoso sociólogo Florestan Fernandes (1979), o que ocorreu com a reforma foi a apropriação conservadora de algumas pautas inevitáveis em uma "reforma universitária consentida", preservando o caráter elitista e o distanciamento da realidade brasileira por parte das instituições de ensino superior. Para ele, a reforma que ocorreu não agradou a ninguém além dos conservadores que tomaram as rédeas do processo, deixando de lado as aspirações do movimento estudantil e até mesmo dos organismos criados pelos Estados Unidos para ajudar a América Latina (MEC-USAID). Em uma leitura que vai ao encontro da análise de Fernandes, Lalo Minto (2011, p. 173) resume, dizendo que as mudanças da reforma: “... modificaram a fisionomia do ensino, porém, não o alteraram estruturalmente. A lógica da universidade conglomerada, heterônoma e repelente a mudanças não se modificou substancialmente. 'Mudaram' para manter tudo como antes."

Em segundo lugar, e o que vai no cerne da questão aqui tratada, é a atuação dos governos militares na repressão político-ideológica e, dentro disso, o transbordamento dessa perseguição para o cerceamento da liberdade acadêmica. Nesse aspecto, o discurso militar era bastante direto, pois, segundo Cunha (1988, p. 21), preconizava a correção de “certos 'desvios' esquerdistas, ou melhor, [...] o expurgo dos esquerdistas que estariam infiltrados nas instituições de ensino superior". Nas duas seções seguintes tratamos desse aspecto.

\subsection{A burocracia de inteligência e informação}

A ditadura militar brasileira começou a construir o aparato de inteligência que serviria à repressão já em junho de 1964, logo após o golpe, com a criação do Serviço Nacional de Informação (SNI) (Stepan, 1988). A questão da informação foi marca, inclusive, da coordenação do golpe, que envolveu militares da Escola Superior de Guerra (ESG, criada em 1949), além de instituições civis como o Instituto Brasileiro de Ação Democrática (IBAD, de 1959) e o IPES (de 1962). Essas instituições foram responsáveis pelo levantamento de cerca de 400.000 dossiês detalhados a respeito de cidadãos brasileiros (Alves, 1985, p. 25). O próprio general 
Golbery do Couto e Silva, um dos comandantes do IPES e importante intelectual da Doutrina de Segurança Nacional brasileira, admitiu que a instituição agiu na desestabilização do governo de João Goulart (Wasserman, 2006).

Há duas periodizações que consideramos de interesse para compreender a intervenção da ditadura militar no meio universitário. Mansan (2013) classifica a repressão de acordo com o modo de operação dos órgãos de inteligência do governo brasileiro. Teríamos, então, os períodos: colaborativo (1964-1967), internalizado (1967-1979) e dissimulado (1979-1983). Já Holzmann et al. (2008) escrevem sobre duas "ondas de violência", que teriam acontecido antes e depois do endurecimento do regime com o AI-5. Essas ondas guardam certa relação com o caráter institucional da periodização de Mansan (2013).

Durante o período colaborativo, as informações levantadas pelos órgãos de segurança eram coletadas através de colaboradores da sociedade civil, o que no âmbito universitário significava principalmente os professores e técnicos (Mansan, 2010). Já o modelo internalizado (1967-1979) coincide com a emergência do poder da chamada "linha dura" do Exército e com a edição do AI-5. A Reforma Administrativa de 1967 também teve efeitos sobre as mudanças no modus operandi da intervenção, uma vez que a descentralização era um dos seus princípios norteadores. A criação das Divisões de Segurança e Informação (DSI) foi marca do período e, mais especificamente, para ação sobre as universidades e demais autarquias foram criadas as Assessorias de Segurança e Informação (ASI) ${ }^{3}$ (Mansan, 2010; Fagundes, 2013). Segundo Motta (2008, p. 37), entre as principais funções das ASI estavam (1) criar uma espécie de filtro ideológico, de modo a impedir o ingresso de elementos subversivos nas universidades; (2) controlar manifestações estudantis em geral; (3) controlar as atividades dos docentes, principalmente no que diz respeito a viagens internacionais; e, (4) garantir a disseminação da propaganda do governo. Finalmente, o período dissimulado iniciou-se com a dissolução das ASI, em 1979. A partir daí a vigilância passa a ser mais acanhada e menos formal, caracterizada mais pela permanência de militares anteriormente ligados às ASI como funcionários dentro das universidades e autarquias. Vale também apontar que 1979 foi o ano da Lei da Anistia.

\subsection{Ciclos de repressão e exemplos da política do medo}

A chamada "primeira onda de violência" iniciou-se poucos dias após o golpe militar, praticamente coincidindo com a fase colaborativa. A instituição que mais sofreu nesse período foi a Universidade de Brasília (UnB). Recém-fundada em 1962, idealizada por Darcy Ribeiro e Anísio Teixeira, autorizada por João Goulart, a UnB

(3) O mesmo órgão também utilizava a nomenclatura de AESI (Assessoria Especial de Segurança e Informação), dependendo da instituição onde estivesse instalado. 
foi um alvo certo do conservadorismo do novo regime de 1964. A instituição foi invadida por tropas militares duas vezes e teve diversos professores demitidos, principalmente entre 1964 e 1965. No ocorrido mais emblemático, em 9 de outubro de 1965, o reitor Laerte de Carvalho demitiu 15 professores. Em protesto, outros 223 professores pediram demissão. Somados, os demitidos e demissionários correspondiam a $79 \%$ do corpo docente (Salmeron, 1999).

Já o início da "segunda onda de violência" é concomitante ao do período internalizado. O Ministério da Educação, então, começa a coordenar a vigilância e as medidas punitivas de forma direta (Mansan, 2010, p. 80). A partir dessa época, a perseguição ideológica, sem dúvida, fica mais evidente e marcante. Os sucessivos episódios de demissões de professores da USP exemplificam bem a perseguição na academia durante esse período. Florestan Fernandes, Jayme Tiomno e João Batista Villanova Artigas foram alguns dos forçados à aposentadoria (Adusp, 2004, p. 45). O protesto do então reitor Hélio Lourenço de Oliveira resultou em um decreto através do qual foram demitidos, ou forçosamente aposentados, além do próprio reitor, outros 23 professores. Entre eles estavam Paul Singer, Otávio Ianni e Fernando Henrique Cardoso (ADusp, 2004, p. 48).

Outras universidades sofreram processos semelhantes de perseguição ideológica e patrulhamento. Holzmann et al. (2008) e Mansan (2009) analisam o período para a Universidade Federal do Rio Grande do Sul (UFRGS), enquanto Brito (2014) e Clemente (2006) tratam da Universidade Federal da Bahia. Já a Universidade Estadual de Campinas (Unicamp), segundo interpretação corrente na literatura sobre o período, apresentava uma realidade distinta. Nesse cenário, a figura do reitor Zeferino Vaz foi de extrema importância, pois, além de implementar mudanças modernizantes, antes mesmo da reforma universitária, ele trouxe nomes importantes e promissores para o corpo docente da nova instituição campineira, não se importando com suas ideologias políticas e protegendo-os da perseguição do regime (Gomes, 2007).

Contudo, vale notar que apesar de ser apresentado como importante defensor da autonomia universitária, ele também foi reitor da UnB durante exatamente os primeiros meses da ditadura, desempenhando papel bem diferente nessa universidade do Planalto Central, como nos mostram Salmeron (1999) e Gomes (2007). Em contraposição à literatura que defende a atuação de Vaz na Unicamp, Caio Toledo questiona a ideia do referido reitor enquanto um "combativo anticomunista fora da universidade, mas que, ao adentrá-la, ensarilhava as armas e rendia-se aos valores da tolerância e pluralismo teórico-ideológico" (Toledo, 2015, p. 122). Nesse tocante, cita-se tanto sua proximidade com as forças armadas e atuação enquanto ocupava o cargo de reitor da UnB, quanto episódios em que demonstrava certo autoritarismo, além de perseguição a alguns docentes. 
Se a literatura mostra a perseguição e o cerceamento da liberdade acadêmica, no que segue, pretendemos avaliar como esse contexto se coaduna com o que nossas fontes sugerem para o caso específico da economia, em particular para o ensino e a pesquisa da economia de cunho marxista.

\section{Os currículos dos cursos de ciência econômica e a economia política marxista}

Analisando os currículos das escolas de economia para os quais conseguimos acesso, é possível dizer que, a partir da documentação, não se observa interferência nas grades curriculares, especialmente no sentido de proibir a existência de disciplinas, ou, ainda, com ingerência no conteúdo das disciplinas existentes. Obtivemos documentos das seguintes universidades: USP, UFRGS, UFPR, UFRJ, UFMG e UFBA ${ }^{4}$.

Nesse ponto, antes de prosseguirmos, é preciso anotar o que a historiografia registra sobre o marxismo no Brasil, em especial dentro da ciência econômica. Essa literatura é pequena, mas mostra que o marxismo no Brasil, desde o início do século XX e até por volta da década de 1980, não tinha grande impacto e disseminação de caráter propriamente científico. Coutinho (2001), autor que procurou sumarizar o influxo das ideias marxistas entre economistas brasileiros no século XX, conclui exatamente nesse sentido. As razões apontadas para tal são o que ele chama de isolamento da teoria e, principalmente, a subordinação da discussão econômica de caráter mais sofisticado aos debates de natureza de ação política, isso somado às dificuldades de acesso a material bibliográfico (Konder, 1984; Coutinho, 2001). Adicionalmente, segundo Bielschowsky (1997, p. 88), o pensamento marxista mais elaborado em economia esteve sempre subordinado ao desenvolvimentismo. Por exemplo, mesmo uma instituição como o Instituto Superior de Estudos Brasileiros (ISEB), em geral mostrado como um instituto de esquerda, na realidade sustentava um projeto desenvolvimentista (Bresser-Pereira, 2004) ${ }^{5}$. Portanto, se constatamos a falta do marxismo na academia econômica brasileira das décadas do regime militar, em boa medida isso pode ser produto da falta de uma rede de discussão, pesquisa e, consequentemente, da difusão desse tipo de teoria econômica. Lidiane Rodrigues (2011), analisando o grupo de estudos de "O Capital" "Seminários em Marx", mostra como esse grupo foi pioneiro no que chama de "marxismo universitário",

(4) Para a UFMG e a UFPR obtivemos acesso aos programas das disciplinas, assim como às grades dos cursos. Da USP pudemos levantar apenas uma lista de disciplinas ofertadas, assim como na UFBA (nessa última utilizamos os cadernos de classe, sendo que para algumas disciplinas obtivemos os programas). Já a UFRJ e a UFRGS nos forneceram as grades acompanhadas das ementas.

(5) Para um trabalho recente que toma o ISEB como instituição de esquerda, ver Czajka (2010).

(6) O grupo "Seminários em Marx" foi o mais famoso dos grupos de estudos que tinham a finalidade de estudar a obra do autor alemão. Idealizado pelo filósofo José Arthur Giannotti, foi concebido para que houvesse um estudo interdisciplinar da obra O Capital, além de trabalhos de Hilferding, Rosa Luxemburg, Keynes e Weber. Participavam sociólogos, filósofos, economistas e historiadores como Fernando Henrique Cardoso, Paul Israel Singer, Fernando Novais e Octavio Ianni. O grupo polemizava muito com outros intelectuais, principalmente os desenvolvimentistas do Instituto Superior de Estudos Brasileiros (ISEB), que tinha Roberto Campos como uma das principais figuras. Ver Giannotti (1998). 
muito incipiente no Brasil do início da década de $1960^{7}$. Ademais, a recepção de Marx no Brasil dividiu-se entre o ambiente acadêmico e o de intelectuais de esquerda, principalmente ligados ao Partido Comunista Brasileiro (PCB). Na filosofia, por exemplo, foi o referido grupo de estudos um dos grandes responsáveis por superar a barreira imposta ao autor alemão pela tradição francófona existente no país (Arantes, 2007) ${ }^{8}$. O caso do estudo dos fenômenos econômicos seguiu divisão similar, como mostra Mantega (2007). Entretanto, mesmo nesse cenário, havia a referência a Marx, ao marxismo e ao socialismo nos cursos de ciências econômicas do período em foco.

Sobre o surgimento da ciência econômica e dos cursos de economia no país podemos apontar dois caminhos pelos quais eles foram introduzidos. O primeiro, ligado ao ensino da disciplina, têm origem que remonta a José da Silva Lisboa (17561835), o Visconde de Cairu, e suas “Aulas Públicas de Economia Política”. Mesmo sem se materializarem em as aulas propriamente, a obra de Lisboa teve grande influência na maneira como a economia seria ministrada dentro dos cursos de engenharia e direito, locais onde alguns intelectuais importantes travaram seu primeiro contato com o estudo de economia (Saes et al, 2014). O segundo caminho é aquele que originou os cursos superiores formais de ciências econômicas. Os primeiros títulos de economista foram entregues por cursos que lecionavam uma mistura de contabilidade, economia e ciências atuariais. Isso foi, de certo modo, um desdobramento das "Aulas de Comércio" iniciadas ainda no início do século XIX (Castro, 2001). Apesar de estabelecidas no início do século, as grades curriculares dessas aulas só foram regulamentadas, por D. Pedro II, na década de 1840 (Castro, 2001). Foi somente em 1945, dentro da Universidade do Brasil, agora UFRJ, que economia foi um curso oferecido separado das demais disciplinas anteriormente citadas. Esse esforço teve como protagonista o engenheiro e economista autodidata Eugênio Gudin.

Dezoito anos depois, em 1963, o curso foi reformulado pelo recém-criado (1961) Conselho Federal de Educação (CFE), com o estabelecimento de um currículo mínimo. Em 1968, depois da reforma universitária do regime, alguns cursos de economia começaram a usar a maior flexibilidade permitida pelas novas normas para alterar suas grades em relação ao antigo currículo mínimo. Assim, percebemos mudanças no sentido de uma certa diferenciação dos diversos cursos no

(7) Rodrigues (2011, passim) caracteriza o marxismo universitário como aquele que se contrapõe ao marxismo político, prático, de ação. O marxismo universitário é a inserção/legitimação/espraio das teorias marxistas como temas de pesquisa, de aulas, de teses e dissertações, também como conteúdo de disciplinas e cursos nas mais diversas áreas. De certa maneira, a ascensão do marxismo universitário, segundo Rodrigues (2011, p. 56), como processo de legitimação, acontece na medida em que se distancia do marxismo político.

(8) Frederico (2007) é um autor que fala também nesse sentido, ao mostrar que a recepção de Lukács é caso semelhante. O autor fala também de Marx no departamento de sociologia da USP, onde, apesar de sua obra ser abordada, isso era feito apenas da perspectiva dela enquanto uma contribuição como um clássico alemão, sem referência à importância do materialismo histórico. 
país, que passavam a atender a vocação da composição de cada departamento (Nogueira; Nunes; Barroso, 2005, p. 8, 11-19). Outra reformulação profunda só aconteceria em 1984 (Parecer CNE/CES n. 95/2007, p. 10). Dentro dos arquivos pesquisados, a documentação mais interessante é a que se refere ao período da fase internalizada, pois foi nesse tempo que o regime procurou manter um controle ideológico mais rigoroso.

Pegue-se, primeiro, o caso da UFRJ. Dessa instituição temos grades para um ano anterior à reforma $(1967)^{9} \mathrm{e}$, para outro, posterior (1972), bem como as ementas para o ano $1973^{10}$. Enquanto a grade daquele primeiro ano segue quase estritamente o currículo mínimo do CFE, para 1972 temos a inclusão de algumas disciplinas diferentes. Nas ementas de 1973, aparecem explicitamente conteúdos de caráter marxista, em especial no programa de "História Econômica Geral e Formação Econômica do Brasil" (HEG \& FEB). Nessa disciplina, fica bem exposto o caráter marxista da abordagem do tema histórico, pois na ementa constam "transição do feudalismo para o capitalismo", "revoluções burguesas", "o imperialismo e a nova expansão colonial", entre outros termos que apontam no mesmo sentido. A outra disciplina em que Marx aparece, considerado como um "clássico", é "Sociologia" (UFRJ, 1973).

Na UFPR, também a disciplina de HEG \& FEB apresenta conteúdo e abordagem marxistas. Para o ano de 1969, a ementa do curso tinha entre a bibliografia o livro "História Econômica do Brasil", de Caio Prado Júnior. A presença de um livro de Prado Júnior na bibliografia é significativa, pois dois outros livros do autor foram censurados na década de 1960 (Reimão, 2014, p. 82) ${ }^{11}$. O programa da disciplina apresenta conteúdos como "economias pré-capitalistas", "evolução do capitalismo" e, dentro desse último item, "a evolução econômica da Europa: a subida da burguesia ao poder", entre outros. Em "História do Pensamento Econômico" (HPE), "Marx e Engels" estão presentes como um tópico dentro de "Reações aos Clássicos" (UFPR, 1969)"

Em 1966, o programa de HPE da UFMG mostrava um tópico de "Marxismo" com a discussão, inclusive, da "Situação Atual do Marxismo". Adiante, no item "Escolas Econômicas Cristãs", vê-se "Socialismo Católico: o partido da esquerda". No programa de HEG \& FEB tem-se "O Mundo Socialista", mas não encontramos evidência de que a abordagem da história tinha traços do método do materialismo histórico (UFMG, 1966) ${ }^{13}$. Em HPE, veremos que um dos nossos

(9) A grade é para o início do ano letivo, portanto elaborada antes da reforma daquele ano.

(10) Documentos obtidos junto à Secretaria de Graduação do Instituto de Economia da UFRJ.

(11) Os livros censurados foram "O Mundo do Socialismo", de 1962, e "A Revolução Brasileira”, de 1966.

(12) A documentação da UFPR foi cedida pela Coordenação do Curso de Graduação em Ciências Econômicas.

(13) Os arquivos foram obtidos na Seção de Ensino da Faculdade de Ciências Econômicas da UFMG. 
entrevistados comenta sobre como Marx era apresentado sem grande destaque nesse curso. Enfim, para a UFMG, devemos apenas registrar que há menção aos conteúdos marxistas, mas sem concluirmos algo em relação à abordagem.

Já na UFBA, não encontramos grades organizadas, portanto reconstruímos o elenco de disciplinas com base em diários de classe, chegando à conclusão de que sua grade deveria seguir o currículo mínimo de 1963. A ementa conseguida para o ano de 1969, da disciplina de HEG \& FEB, apresenta apenas um conteúdo como "Origens do Capitalismo" (UFBA, 1969). Para a Universidade Federal do Rio Grande do Sul (UFRGS), as ementas do ano de 1973 são bastante sintéticas e, por conseguinte, é difícil concluir que efetivamente havia conteúdo marxista em disciplinas como HEG \& FEB e HPE (UFRGS, 1973). Desse modo, para UFBA e UFRGS, também não se pode afirmar traços de uma abordagem marxista nas disciplinas históricas, embora, é claro, Marx seja mencionado.

Da Universidade de São Paulo (USP), as informações são poucas, pois apenas conseguimos o elenco de disciplinas e o ano de início de sua presença na grade $^{14}$. Algumas dessas disciplinas poderiam discutir temas marxistas e relacionados aos países do bloco socialista, tomando por base o que acontecia nas outras universidades. As disciplinas são, novamente, "Formação Econômica do Brasil I e II" e HPE, ambas com início em 1976 (HEG aparece separada). Em relação aos anos de início da presença dessas disciplinas na grade, assinala-se que elas já constavam da grade de 1964 apresentada por Canabrava (1984, v. 1, p. 438-440). Aqui, só podemos aventar a possibilidade de que tais disciplinas mencionassem Marx.

Outros documentos para o período posterior ao internalizado foram conseguidos junto às instituições que tratamos (UFMG, 1979; USP, 1981). A comparação é interessante especialmente para a UFMG, com um grande crescimento na oferta de disciplinas com conteúdo marxista. Essa evidência poderia apontar, em um primeiro plano, no sentido de que havia um desejo por parte dos membros do corpo docente de ofertar disciplinas de cunho marxista, e que elas não eram ofertadas antes por conta da repressão. Porém, ao mesmo tempo, ela pode indicar que membros do corpo docente tiveram formação durante o período mais repressivo para lecionar tais disciplinas. É para a UFMG que o contraste é mais evidente.

Em conclusão, vê-se que a repressão não eliminou absolutamente as discussões sobre marxismo ou socialismo dos cursos de economia brasileiros, mesmo durante o período mais duro do regime. Mais marcantes são dois dos casos analisados. A presença da abordagem e conteúdo marxistas na grade da UFPR contrasta com a posição do reitor da época, Flávio Suplicy de Lacerda, que dirigiu a

(14) Informações oferecidas pela Seção do Aluno da Faculdade de Economia, Administração e Contabilidade da USP. 
universidade entre 1967-1971 e fora ex-ministro da educação de Castelo Branco. Sua atuação tanto como ministro quanto como reitor reprimiu duramente o movimento estudantil. Nesse tocante, também chama a atenção que na UFRJ houvesse o programa de uma disciplina calcado na perspectiva do materialismo histórico, isso em pleno período do presidente Médici. Adicionalmente, vê-se que a discussão marxista era, sem dúvida, incipiente, mas não se pode dizer que houve veto total à menção e mesmo à adoção de abordagem marxista. Isso pode ter ocorrido tanto em razão de negligência dos órgãos de repressão, como porque não havia uma repressão sistemática em relação a programas e conteúdo. Pensamos que os depoimentos ajudam a esclarecer melhor alguns dos pontos levantados.

\section{Memória: história oral e a presença do marxismo na visão de docentes e discentes da época}

A história oral está ligada, em primeiro lugar, à busca de evidências sobre fatos, pessoas, grupos e acontecimentos sem registros escritos e, por isso, um de seus predicados é dar espaço a grupos oprimidos, perseguidos e, sobre os quais, justamente por suas características marginais, não há registros históricos completos. Ela preenche lacunas nos registros oficiais, enfim. Por outro lado, a história oral fornece uma perspectiva mais subjetiva, o que serve exatamente aos propósitos de se obter impressões de cunho pessoal e de extrair os impactos psicológicos de determinadas experiências, em especial as traumáticas e marginalizantes (Poniatowska, 1988; Halbmayr, 2009). Em relação ao período da ditadura, a título de exemplo, podemos citar os estudos de Freire Júnior, Videira e Ribeiro Filho (2009), com depoimentos de físicos, e o de Lourenço (2010), que entrevistou professores de história do ensino básico.

Na história do pensamento econômico, o uso da história oral teve destaque especialmente nas famosas entrevistas conduzidas por Arjo Klamer (1983) em "Conversations with Economists". Esse projeto foi replicado no Brasil, nos dois conhecidos volumes de Biderman, Cozac e Rego (1996) e Mantega e Rego (1999). No que diz respeito à abordagem do nosso trabalho, porém, o trabalho de Mata e Lee (2007) é o que serve melhor de exemplo. Nesse trabalho, os autores investigam e procuram retratar uma experiência pessoal na emergência de uma associação de economistas heterodoxos norte-americanos, a Union for Radical Political Economy. Ao contrário das entrevistas conduzidas por Klamer e pelos economistas brasileiros, Mata e Lee (2007) tinham um objetivo mais preciso: reconstruir uma experiência pessoal na formação de uma associação de dissidentes da economia tradicional. Nesse trabalho, portanto, a perspectiva psicológica ganha destaque.

Nossas entrevistas abordaram uma série de temas que dizem respeito à pesquisa e ensino de economia marxista no Brasil após golpe de 1964. Os temas que consideramos mais relevantes e que se destacaram nos depoimentos foram, 
principalmente, três: (1) a possibilidade e o modo de acesso à discussão teórica no campo do marxismo; (2) o modo como se dava a perseguição dentro de cada uma das universidades; e (3) a percepção de cada um quanto aos cerceamentos do governo em torno do tópico específico desse estudo, a economia marxista.

\subsection{Acesso ao estudo de Marx, do marxismo ou do socialismo}

É fundamental perguntar se o regime encontrou pesquisa e ensino organizados em teoria econômica marxista nas universidades. A respeito disso, podemos dizer que, em adição à pequena existência de conteúdos marxistas nos cursos, como visto acima através das fontes apresentadas, amealhamos evidências nas entrevistas que apontam no mesmo sentido - conclusão obtida através de outra metodologia por Coutinho (2001).

Dois relatos sobre o ensino na USP anterior ao golpe dão conta da falta de discussão qualificada em teoria econômica marxista. No sentido da falta de qualificação em geral do corpo docente, Delfim Netto (2015), graduado em 1951, marca que a USP sempre foi muito eclética, mas em sua época de estudante contava praticamente só com professores autodidatas ${ }^{15}$. Paul Singer (2014), aluno de Delfim e graduado em 1959, coloca, de maneira mais específica para o nosso tema: “... o curso que eu fiz, Marx (...) era muito pouco mencionado, e pior ainda, os professores não o conheciam e faziam erro, bobagem. Não era proposital, é que eles tinham um conhecimento pequeno e antipático".

Já Antônio Plínio Pires de Moura (2014), graduado em 1961, na UFBA, anota que sua faculdade tinha fama "esquerdista", porém, era, na realidade, nacionaldesenvolvimentista. Não havia discussão propriamente marxista em sua universidade, diz o entrevistado. Isso vai no sentido do que afirma Bielschowsky (1997, p. 88), isto é, de que o marxismo esteve sempre fundido com desenvolvimentismo. Bresser-Pereira (2014), em sua entrevista, também atesta que a influência de Marx nos economistas brasileiros era visível através das ideias desenvolvimentistas e, um pouco mais tarde, da teoria da dependência.

Ao contrário dos graduados em economia, como Moura, Netto e Singer, Theotônio dos Santos e Luiz Gonzaga Belluzzo nos dão relatos diferentes. Esse último formou-se em Direito no ano de 1965, mas frequentou a faculdade de Ciências Sociais da USP durante os anos anteriores ao regime. Assim, Belluzzo foi aluno de José Arthur Giannotti e Fernando Henrique Cardoso, entre outros, que

(15) Na época de Delfim Netto (2015), segundo o mesmo, um dos poucos professores "profissionais" do Departamento era Paul Hugon, professor de história do pensamento econômico. Quanto à pluralidade, Delfim afirma que professores de excelência ligados ao marxismo e aos movimentos socialistas, como Paul Singer e Lenina Pomeranz, foram aceitos sem problemas no Departamento de Economia da USP. Os dois entraram para o Departamento como professores logo após a conclusão de suas graduações, segundo seus currículos Lattes, em 1960. Portanto, antes do golpe de 1964. 
estavam se dedicando à leitura de "O Capital", no já referido grupo de estudos "Seminários em Marx". Em decorrência disso, Belluzzo teve acesso à uma discussão de maior qualidade e interdisciplinar sobre esse tema (Belluzzo, 2014). Ele é, portanto, dentre os nossos entrevistados, talvez o primeiro que trava contato com o "marxismo universitário". Já Santos cursou Sociologia, Política e Administração Pública, na UFMG, graduando-se em 1961. Ele nos conta que teve contato com autores como Henri Lefebvre, além de textos do próprio Marx que eram desconhecidos ou pouco usados até então, como os "Grundrisse" ou a "Contribuição para a Crítica da Economia Política". Além disso, ele faz um apontamento muito importante, no sentido dos movimentos sociais e do espraio e contato com a literatura fora do círculo acadêmico (Santos, 2015).

Santos, então, representa um traço bem característico do marxismo dos anos 1950 e 1960 no Brasil. Muito mais do que na academia, o espaço desse pensamento estava nos movimentos políticos (incluindo os estudantis). Os grupos com os quais Santos se envolveu vão, em conjunto com outros, fundar a Organização Marxista Revolucionária Política Operária (Polop). Em sua experiência pessoal, portanto, a universidade se mistura com o movimento político. Em 1961, ano de formação da Polop, ele vai para a UnB. Na capital federal, a universidade progressista se mostra um ambiente propício às discussões de teorias marxistas. O grupo de Santos (2015), que contava com sua esposa Vânia Bambirra, além de Rui Mauro Marini, entre outros, conhecia e estudava o trabalho de economistas marxistas como Paul Baran e Paul Sweezy, especialmente através de periódicos como o Monthly Review. Pouco conhecido fora de São Paulo, esse grupo vai ter seu trabalho esmigalhado pela violentíssima intervenção dos primeiros tempos do golpe na $\mathrm{UnB}$, parte da primeira onda de violências que comentamos acima.

A importância das discussões em movimentos trabalhistas e políticos também se revela em um comentário de Paul Singer (2014), que se lembra de notar os erros de seus professores, pois havia estudado Marx em sua passagem pelo movimento sindical. Com o respeito devido, Singer confessa, ele era capaz de corrigir seus professores, porque havia estudado marxismo na época de sua participação nos movimentos sindicais, antes de entrar para a universidade. Por sua vez, Bresser-Pereira (2014) não pode ser considerado um marxista, mas na sua entrevista surge também o fato de que seu primeiro contato com ideias marxistas foi através do movimento da Juventude Católica (JUC). João Antonio de Paula (2014) e Claus Germer (2014), estudantes nos anos 1960-70, da mesma forma, tiveram seus primeiros contatos com o marxismo através dos movimentos sindicais e estudantis. Paula (2014) cita que, durante sua graduação em economia na UFMG, o marxismo era ensinado em HPE, mas apenas como uma "curiosidade".

Pensamos que esses relatos colocam dois aspectos importantes para o nosso assunto. Primeiro, a inexistência de discussão academicamente bem articulada, em 
economia, da teoria marxista. Entre os entrevistados, quem travou contato com o "marxismo universitário" o fez em um curso de Ciências Sociais, o que aconteceu com Belluzzo e Santos. Em boa medida, quando chega a ditadura militar, a discussão marxista está majoritariamente fora da academia, pois o marxismo universitário apenas dava seus primeiríssimos passos e, em especial, era rarefeito nos cursos e departamentos de economia.

\subsection{Os diferentes centros e a perseguição acadêmica}

O modo como o golpe militar de 1964 influenciou o ambiente universitário foi bem diverso em diferentes instituições. A UnB sofreu pesadamente, como vimos. Theotônio dos Santos tinha acabado de finalizar seu mestrado nessa instituição e lecionava no Departamento de Ciência Política. Suas palavras dão alguma dimensão à perseguição que sofreu:

Em 1964, quatro dias depois do golpe, eu fui demitido da Universidade de Brasília pelo reitor, que depois se converteu em uma grande figura, o Zeferino Vaz. Fui um dos quatro que saíram primeiro, depois vieram outros. Foi muito rápido, parece que já tinha algo antes preparado.

Eu fui informado vagamente, mas já tinha um processo, com uma pequena condenação de quatro anos, que envolveu exatamente a mim, ao Rui Mauro Marini e à Vânia, em torno das atividades da POLOP depois do golpe, uns 3 ou 4 meses depois. Isso eu não conhecia bem. $\mathrm{O}$ [processo] que existia mais forte era em Minas, e que terminou no final de 1965 com uma condenação de 15 anos de prisão. Aí ficou difícil a vida clandestina (Santos, 2015)

Santos, então, passa quase todo o período da ditadura militar fora do país, retornando apenas após a anistia, em 1979.

Aparentemente, em oposição a esse cenário fica a Unicamp. Como era uma universidade nova, segundo Belluzzo (2014), os militares só começariam a prestar atenção à Unicamp a partir de meados dos anos 1970, quando o processo de abertura estava para ser iniciado. Além disso, o papel fundamental de Zeferino Vaz na garantia da liberdade acadêmica na Unicamp foi crucial ${ }^{16}$. Belluzzo (2014) relata um ocorrido, demonstrando a ousadia e o firme propósito de Zeferino de defender a independência acadêmica frente ao regime:

Para você ter uma ideia, em 1975 houve uma comemoração (...) do aniversário da revolução. Ele levou a mim e ao João Manoel no quartel. Ele fez o discurso, foi convidado para fazer o discurso, sendo que era uma cerimônia seguida de um coquetel. E o então comandante do quartel chegou para ele, eu e o João

(16) Levantando dúvidas em relação ao papel de Zeferino Vaz, Toledo (2015) insiste na possibilidade de o caso especial de falta de repressão à Unicamp no período se dar graças à falta de movimentos organizados que lutassem ativamente contra a ditadura dentro do campus. 
Manoel assistindo a isso, e disse assim: "A sua universidade está cheia de comunistas". E ele [Zeferino, disse:] "Coronel, o senhor entende de forças armadas e eu entendo de universidade. Na minha universidade os professores têm liberdade total de dizer o que eles pensam.

Outros reitores que aparecem nas entrevistas são Miguel Calmon, reitor da UFBA entre 1964-67, e Eduardo Cisalpino, reitor da UFMG entre 1974-78. De acordo com Moura (2014), usando seu prestígio político, Calmon foi responsável por acolher na UFBA vários professores demitidos da UnB. Por sua vez, Paula (2014) menciona que sua contratação como professor, em 1976, precisou do apoio de Cisalpino ${ }^{17}$.

Outro aspecto importante é o da existência de órgãos do regime dentro das universidades. Nesse ponto surge um contraste em relação à ideia da Unicamp como uma "ilha" de liberdade acadêmica. Belluzzo (2014), na mesma entrevista, afirma que havia aparato de inteligência em Campinas. Em 1975, inclusive, ele tomou conhecimento de que fazia parte de uma lista de "marcados para morrer", juntamente com César Lattes (físico), Hilda Hilst (poeta) e Sérgio Arouca (médico). Acabou saindo do país brevemente por conta dessa ameaça. Recentemente, a Unicamp constituiu uma comissão da verdade para estudar os ocorridos durante o regime militar. Dentre os integrantes da comissão estava o professor de economia Wilson Cano (2015), que relata:

Cada um de nós economistas deixou seu emprego para vir montar a área de humanidades, cujo piloto era a economia. Não poderíamos entrar em nenhuma outra universidade pública; na USP, jamais. Jamais teríamos montado um Instituto de Filosofia e Ciências Humanas ou um Instituto de Economia como aqui, com enorme grau de liberdade e acessibilidade crítica, expostas em nossas aulas, declarações e artigos. A Unicamp foi uma anomalia em relação ao resto da academia, mas não foi uma ilha porque aqui dentro também tinha gente da ditadura.

Na UFBA, Moura (2014) também nota que o governo tinha órgãos de inteligência em funcionamento. Segundo o entrevistado, eles catalogavam os alunos através do requerimento de uma foto extra durante a confecção da carteirinha de estudante. Além disso, ele afirma que existiam agentes provocadores presentes entre os estudantes. "Dentro da sala [esses agitadores] eram os mais esquerdistas, e você já sabia que era agente provocador. Então todo mundo [ficou] pisando em ovos durante esse período..." (Moura, 2014) ${ }^{18}$.

Não era em todos os lugares essas assessorias foram notadas pelos professores. No caso da USP, nem Netto (2015), nem Singer (2014) confirmaram a

(17) Cisalpino relata um pouco da sua experiência ao lidar com a ditadura em uma entrevista. Ver Santos (2007).

(18) Lourenço (2010) também obtém de seus entrevistados relatos sobre agentes infiltrados na universidade. 
existência da mesma. Delfim, inclusive, nega a existência desse órgão dentro do Ministério da Fazenda, onde ocupava o cargo de ministro na data da criação das ASI. Tampouco na UFMG Paula (2014) relata notar a atuação dos órgãos de segurança organizados dentro da Faculdade de Ciências Econômicas. No entanto, segundo Paula (2014), havia um coronel, secretário da Faculdade de Ciências Econômicas, que censurava publicações do Diretório Acadêmico. O único entrevistado que era ligado a uma instituição particular, Bresser-Pereira (2014), professor da FGV de São Paulo, relata que não percebia nenhuma intervenção dentro da faculdade, em especial porque era uma faculdade financiada pelo empresariado paulista.

Uma observação interessante aparece na entrevista de Claus Germer (2014), estudante de mestrado na USP-Esalq na década de 1970. Ele relata demissões de professores, mas observa que os demitidos "não [eram] necessariamente marxistas, porque não era esse o ponto, não era especificamente esse o ponto". O caráter das perseguições era muito mais amplo, e obviamente não só marxistas ou comunistas se opunham ao regime. Para ele, a oposição ao governo era o ponto central, e não a ligação do acadêmico a algum tipo de teoria econômica ou social. Essa informação se coaduna com o fato de que outros cientistas, das ciências naturais, também foram perseguidos.

Nesses casos, uma conclusão que se pode retirar das entrevistas é a de que diferentes grupos e universidades sofreram diferentes tipos e graus de intervenção. O caso da Unicamp é emblemático no sentido da liberdade, embora com a qualificação relatada acima, enquanto os acontecidos na UnB destacam-se pelo inverso. É preciso enfatizar a importante atuação de reitores que se opuseram às perseguições, possivelmente ciosos do valor fundamental para a vida universitária que é a liberdade acadêmica (ou mesmo porque simplesmente desejavam garantir o funcionamento regular da instituição).

\subsection{Interferências no ensino e pesquisa em economia e a "autocensura"}

Nesse assunto das entrevistas surge o que talvez seja o ponto mais interessante levantado pelos entrevistados. Como vimos através de documentos das faculdades de economia, não houve uma eliminação completa e absoluta dos conteúdos marxistas, das menções à Marx e mesmo da abordagem marxista de assuntos como a história econômica - nisso, considerado o qualificador de que tanto o ensino como a pesquisa eram incipientes. Os professores entrevistados dizem que durante o período do regime as grades não sofreram interferência, e não teriam sido constrangidos no uso de bibliografias e no tratamento de determinados temas. No entanto, e isso parece ser o mais relevante, havia sim um clima de medo e desconfiança, o que levava os acadêmicos ao que pode ser chamado de "autocensura". 
Por exemplo, Moura (2014) nega intervenção e controles diretos sobre o currículo do curso de economia na instituição: "Não. Isso não. Veio haver [interferência] só quando [Jarbas] Passarinho tentou, na reforma de 1969, [com] a MEC-Usaid, resolver o problema de excedentes externos". ${ }^{19}$ No caso da USP, Singer (2014) observa que antes do AI-5 não houve proibição do tratamento de temas, teorias, abordagens - embora os professores já fossem, em geral, avessos à teoria marxista. Após o AI-5, o cenário muda, e os professores de esquerda seriam cassados. Logo após o golpe, o grande impacto sentido no curso de economia, segundo Netto (2015), foi um esvaziamento do corpo docente porque muitos teriam ido trabalhar no governo - cerca de dez, reduzindo sensivelmente o número de professores. Isso pode ser tomado como mais uma evidência de que os professores da USP eram avessos às ideologias contrárias ao regime de exceção, pois foram chamados para atuar no governo militar.

Já na Unicamp, não houveram tentativas de interferências, conforme nos foi dito pelo professor Belluzzo (2014) e relatado por Cano (2015). Inclusive, Belluzzo lecionava disciplinas com conteúdo marxista. Aluno deste último na Unicamp, Paula (2014), em um período que já anunciava abertura, a partir de 1976, não via nenhum tipo de censura a seu ensino na UFMG: "[s]eja o que acontecia por debaixo dos panos, diretamente nunca houve censura, veto, pressão. Eu dei o curso que eu quis dar, utilizei a bibliografia que eu quis". Moura (2014) também nos relata a inexistência de intervenção nesse sentido, e confirma isso para o período da passagem da década de 1960 para a de 1970.

No entanto, o mais importante e o mais revelador das entrevistas é que o constrangimento poderia não ser sistemático, oficial, mas criava um ambiente de medo e desconfiança que por si mesmo impedia o desenvolvimento de determinados temas nas faculdades de economia. Paula (2014) fala da sua experiência ao chegar na UFMG como aluno: "Quando eu entro para a faculdade [como aluno], a faculdade está sofrendo esse efeito, esse esvaziamento decorrente do golpe, mas mais do que isso, o medo. O medo de falar, o medo de discutir". Mais adiante, em seu mestrado, mesmo na Unicamp, Paula (2014) afirma que era preferível tratar de um autor como Schumpeter, escolhido como tema de sua dissertação: "[v]ocê faz um desvio, porque era realmente problemático, perigoso". Germer (2014), sobre seu período na USPEsalq, aponta na mesma direção: "Aconteceu lá o que acontece nas universidades até hoje, os marxistas fazem uma autocensura, não só os marxistas, o pessoal de esquerda em geral. Porque não estava escrito 'é proibido citar Marx', mas o fato é que era considerado subversivo quem se dedicasse a esse tipo de coisa ..." Mais ainda, é interessante o que Germer (2014) relembra como artifício que utilizou para usar conceitos marxianos enquanto fazia sua dissertação de mestrado: "No texto da

(19) O problema dos excedentes se referia à seleção via vestibular e não tinha relação nenhuma com o conteúdo de disciplinas. 
dissertação... O Weber tem um conceito... Por exemplo, um dos que eu me lembro é o proletário. E ele tinha uma definição bem parecida com a do Marx. Então usei o Weber. Então, tinha esse tipo de coisa. O clima era muito pesado mesmo".

A autocensura também acontecia em publicações de revistas. Essas, assim como qualquer publicação da imprensa brasileira, deveriam passar pela censura do governo militar. Desse modo, por já saber que certos assuntos seriam não seriam aprovados pelos censores, Singer (2014) nos diz que evitava de antemão citações e $\operatorname{assuntos}^{20}$. Já Moura (2014) relata que após a dissolução do diretório dos estudantes, o fechamento de uma gráfica, além da presença dos "provocadores", como já anotamos, "todo mundo [ficou] pisando em ovos". Ademais, apesar de afirmar que não houve cassação de professores mesmo após o AI-5, ele nos diz “... era um clima muito pesado, porque você não podia confiar em ninguém” (Moura, 2014).

Os relatos que apontam no sentido de uma autocensura são muito importantes por duas razões. Primeiro, revelam um caráter psicológico do clima criado pelo regime autoritário. Embora órgãos desse regime não tenham implementado, deliberadamente ou por incapacidade, uma política sistemática de perseguição que atingiria absolutamente tudo que fosse ligado ao marxismo ou à esquerda, o constrangimento existiu pela via do medo e da desconfiança. Além disso, nossas entrevistas mostram a autocensura que outros estudos já apontaram existir entre outros grupos, como por exemplo, entre os artistas (Ortiz, 1988; Reimão, 2014).

\section{Conclusão}

No trabalho acima, procuramos reconstruir a trajetória específica do marxismo no meio acadêmico em economia. Sobressaem, em nossa opinião, a inexistência de uma repressão sistemática e bem organizada sobre ementas e programas de disciplinas, o que, repisemos, deve ser qualificado pela incipiência da pesquisa e educação em teoria econômica marxista nas décadas de 1960 e 1970. Adicionalmente, as entrevistas reforçam que os contatos mais profundos com o marxismo se deram fora da academia e, particularmente, fora dos cursos de economia. Há também o fato de que a intervenção foi diferente em diferentes universidades, com diferentes graus de perseguição e repressão. Nesse ponto, destacam-se as atuações de reitores que tentavam evitar o comprometimento das atividades acadêmicas e, cremos que em especial, da liberdade nesse meio. Finalmente, enfatize-se a existência de um clima de suspeita e medo, que engendrou o que pode ser chamado de autocensura. As entrevistas são cruciais como método histórico para captar essa dimensão de caráter primordialmente psicológico.

(20) Depois de aposentado compulsoriamente da USP, Singer funda junto com vários outros intelectuais o Centro Brasileiro de Análise e Planejamento (Cebrap). 
Ademais, esse último aspecto é importante ao mostrar que os efeitos de um regime autoritário vão além da ação (ou inação) meramente oficiais, constrangendo pela via psicológica um valor crucial para a existência de uma academia forte: a liberdade de pesquisar e ensinar.

\section{Fontes primárias}

UFBA. Caderneta escolar. Curso de Ciências Econômicas. Ministério da Educação e da Cultura, Universidade da Bahia, Faculdade de Ciências Econômicas, 1969.

UFMG. Programas. Curso de Economia. Ministério da Educação e da Cultura, Faculdade de Ciências Econômicas, Universidade Federal de Minas Gerais, 1966.

UFMG. Programas. Ministério da Educação e da Cultura, Faculdade de Ciências Econômicas, Universidade Federal de Minas Gerais, 1979.

UFPR. Programas do curso de ciências econômicas. (Aprovados pela congregação, em seção de 17/3/1969). Ministério da Educação e da Cultura, Universidade Federal do Paraná, Faculdade de Ciências Econômicas, 1969.

UFPR. Programas das disciplinas do curso de economia. Setor de Ciências Sociais Aplicadas, Universidade Federal do Paraná, 1979.

UFRGS, Catálogo de cursos UFRGS. Ministério da Educação e da Cultura, Universidade Federal do Rio Grande do Sul, 1973.

UFRJ. Currículo do curso de economia aprovado pela Congregação em 17/03/1967, 1967.

UFRJ. Currículo do curso de economia (Currículo em vigor a partir de 1972).

UFRJ. Ementas das disciplinas do curso de economia para o ano de 1973 Universidade Federal do Rio de Janeiro, 1973.

USP. Disciplinas ofertas pela FEA-USP entre 1970 e 1989. Formato Excel. 1981.

\section{Entrevistas}

BELLUZZO, Luiz Gonzaga. Entrevista. São Paulo, SP, 2 dez. 2014.

BRESSER-PEREIRA, Luiz Carlos. Entrevista. São Paulo, SP, 1 dez. 2014.

GERMER, Claus Magno. Entrevista. Curitiba, PR, 22 ago. 2014.

MOURA, Antônio Plínio Pires de. Entrevista. Salvador, BA, 29 out. 2014.

NETTO, Antônio Delfim. Entrevista. São Paulo, SP, 27 jan. 2015.

PAULA, João Antônio de. Entrevista. Diamantina, MG, 17 out. 2014.

SANTOS, Theotônio dos. Entrevista. Rio de Janeiro, RJ, 10 fev. 2015.

SINGER, Paul Israel. Entrevista. São Paulo, SP, 29 set. 2014. 


\section{Referências bibliográficas}

ADUSP. O controle ideológico na USP: 1964-1978. São Paulo, SP: Adusp, 2004.

ARANTES, Paulo E. Origens do marxismo filosófico no Brasil. In: MORAES, J. Q. (Org.). História do marxismo no Brasil, v. 2: os influxos teóricos. Campinas, SP: Editora Unicamp, 2007. p. 127-186.

ASSEMBLEIA LEGISLATIVA DO ESTADO DE SÃO PAULO. Caio da Silva Prado Júnior: um perfil biográfico. Disponível em: http://www.al.sp.gov.br/acervo-historico/exposicoes/parlamentarespaulistas/caio prado/Perfil biografico/perfil biografico.htm. Acesso em: 5 jun. 2015.

ALVES, Maria Helena B. Estado e oposição no Brasil (1964-1984). Petrópolis, RJ: Vozes, 1985.

BRESSER-PEREIRA, Luiz. Carlos. O conceito de desenvolvimento do ISEB Rediscutido. DADOS - Revista de Ciências Sociais, v. 47, n. 1, p. 49-84, 2004.

BIDERMAN, Ciro; COZAC, Luis Felipe; REGO, José Márcio. Conversas com economistas brasileiros. São Paulo: Editora 34, 1996. v. 1.

BRITO, Maurício. O golpe de 1964 e a Universidade Federal da Bahia. OPSIS, v. 14, n. 1, p. 301-318, 2014.

CANABRAVA, Alice P. (Coord.). História da Faculdade de Economia e Administração da Universidade de São Paulo, 1946-1981. Ed. por José Augusto Guagliardi. São Paulo: FEA/USP, 1984.

CANO, Wilson. A Unicamp não era uma 'ilha', mas quase. Jornal da Unicamp, n. 625, maio, 2015.

CASTRO, Nivaldo. O Economista: a história da profissão no Brasil. Rio de Janeiro: Cofecon; Corecon-RJ; Corecon-SP, 2001.

CLEMENTE, José Eduardo F. Perseguições, espionagem e resistência: o Instituto de Física da Universidade Federal da Bahia durante a ditadura militar (1964 a 1979). Revista da Sociedade Brasileira de História da Ciência, v. 4, n. 2, p. 129-145, 2006.

COUTINHO, Mauricio C. Incursões marxistas. Estudos Avançados, v. 15, n. 41, p. 35-48, 2001.

CUNHA, Janaína D. A política educacional da ditadura militar e a UFRGS (19641970). In: MOSTRA DE PESQUISA DO ARQUIVO PÚBLICO DO ESTADO DO RIO GRANDE DO SUL, 5, Produzindo história a partir de fontes primárias, v.1, Anais... p. 327-338, 2007. 
CUNHA, Luiz Antônio. A Universidade reformanda: o golpe de 1964 e a modernização do ensino superior. Rio de Janeiro: Francisco Alves, 1988.

CZAJKA, Rodrigo A. Revista civilização brasileira: projeto editorial e resistência cultural. Revista de Sociologia e Política, v. 18, n. 35, p. 95-117, 2010.

FAGUNDES, Pedro E. Universidade e repressão política: o acesso aos documentos da assessoria especial de segurança e informação da Universidade Federal do Espírito Santo (AESI/UFES). Tempo e Argumento, v. 5, n. 10, p. 295-316, 2013.

FAVERO, Maria de Lourdes A. A Universidade no Brasil: das origens à reforma universitária em 1968. Educar, n. 28, p. 17-36, 2006.

FERNANDES, Florestan. Universidade brasileira: reforma ou revolução? São Paulo: Editora Alfa-Omega, 1979.

FREDERICO, Celso. Presença de Lukács na política cultural do PCB e na universidade" In: MORAES, J. Q. (Org.). História do marxismo no Brasil: os influxos teóricos. Campinas, SP: Editora Unicamp, 2007. v. 2. p. 187-228.

FREIRE JÚNIOR, Olival; VIDEIRA, Antônio Augusto; RIBEIRO FILHO, Aurino. Ciência e política durante o Regime Militar (1964-1984): a percepção dos físicos brasileiros. Boletim do Museu Paraense Emílio Goeldi, v. 4, n. 3, p. 479-485, 2009.

GIANNOTTI, José Arthur. Recepções de Marx. Novos Estudos Cebrap, n. 50, p. 115-124, 1998.

GOMES, Eustáquio. $O$ mandarim: história da infância da Unicamp. Campinas: Editora da Unicamp, 2007.

HALBMAYR, B. The ethics of oral history: expectations, responsibilities, and dissociations. In: KURKOWSKA-BUDZAN, M. (Org.); ZAMORSKI, K. Oral history: the challenges of dialogue. Amsterdan: John Benjamins Publishing Company, 2009. p. 195-203.

HOLZMANN et al. Universidade e repressão: os expurgos na UFRGS. Porto Alegre, RS: L\&PM, 2008.

KONDER, Leandro. O marxismo na batalha das ideias. Rio de Janeiro: Editora Nova Fronteira, 1984.

KLAMER, Arjo. Conversations with economists: new classical economists and opponents speak out on the current controversy in macroeconomics. Washington: Rowman \& Littlefield, 1983.

KLEIN, Lúcia; SCHWARTZMAN, Simon. Higher education policies in Brazil: 1970-90. Higher Education, v. 25, p. 21-34, 1993. 
LOURENÇO, Elaine. O ensino de história encontra seu passado: memória da atuação docente durante a ditadura civil-militar. Revista Brasileira de História, v. 30, n. 60, p. 97-120, 2010.

MANSAN, Jaime V. Os expurgos na UFRGS: afastamentos sumários de professores no contexto da Ditadura Civil-Militar (1964 e 1969). 2009. Dissertação (Mestrado)Faculdade de Filosofia e Ciências Humanas, Pontifícia Universidade Católica do Rio Grande do Sul, Porto Alegre, 2009.

MANSAN, Jaime V. O Ministério da Educação e Cultura e o controle do campo do ensino superior durante o governo Costa e Silva (1967-1969). Militares e Política, v. 7, p. 76-99, 2010.

MANSAN, Jaime V. Coerção e controle: a educação superior no Brasil durante a ditadura civil-militar (1964-1988). CLIO - Revista de Pesquisa Histórica, v. 30, n. $2,2013$.

MANTEGA, Guido. Maxismo na economia brasileira. In: MORAES, J. Q. (Org.). História do marxismo no Brasil: os influxos teóricos. Campinas, SP: Editora Unicamp, 2007. v. 2, p. 103-125.

MANTEGA, Guido; REGO, José Márcio. Conversas com economistas brasileiros. São Paulo: Editora 34, 1999. v. 2.

MATA, Tiago; LEE, Frederick. The role of oral history in the historiography of heterodox economics. History of Political Economy, v. 39, n. 1, p. 154-171, 2007.

MINTO, Lalo. W. A educação da 'miséria': particularidade capitalista e educação superior no Brasil. 2011. Tese (Doutorado)-Programa de Pós-Graduação em Educação, Unicamp, Campinas, 2011.

MOTTA, Rodrigo P. S. Os olhos do regime militar brasileiro nos campi. As assessorias de segurança e informações das universidades. Topoi, v. 9, n. 16, p. 30$67,2008$.

NOGUEIRA, André M.; NUNES, Edson; BARROSO, Helena Maria. Mensuração dos conteúdos acadêmicos da educação superior. Rio de Janeiro: Observatório Universitário, 2005. (Documento de Trabalho, n. 42).

ORTIZ, Renato. A moderna tradição brasileira. São Paulo: Brasiliense, 1988.

PONIATOWSKA, Elena. The earthquake: to Carlos Monsivais. The Oral History Review, v. 16, n. 1, p. 7-20, 1988.

REIMÃO, Sandra. Proíbo a publicação e a circulação... - Censura a livros na Ditadura Militar. Estudos Avançados, v. 28, n. 80, p. 75-90, 2014. 
RODRIGUES, Lidiane S. A produção social do marxismo universitário em São Paulo: mestres, discípulos e um "seminário". 2011. Tese (Doutorado)-Programa de Pós-Graduação em História Social, USP, 2011.

SAES, Alexandre et al. Fipe 40 anos: pesquisa, ensino e debate sobre a economia brasileira. São Paulo: Narrativa Um, 2014.

SALMERON, Roberto A. A universidade interrompida: Brasília 1964-1965. Brasília: Editora Universidade de Brasília, 1999.

SANTOS, Tatiana. Entrevista com Eduardo Osório Cisalpino. Boletim da UFMG, v. 33, n. 1580, 2007.

STEPAN, Alfred C. Rethinking military politics: Brazil and the southern cone. Princeton, NJ: Princeton University Press, 1988.

TOLEDO, Caio N. Zeferino Vaz: um reitor de direita que protegia as esquerdas? Germinal: Marxismo e Educação em Debate, v. 7, n. 2, p. 116-132, 2015.

WASSERMAN, Cláudia. O golpe de 1964: tudo o que se perdeu... In: PADRÓS, E. S. (Org.). As ditaduras de segurança nacional: Brasil e Cone Sul. Porto Alegre: Comissão do Acervo Contra a Ditadura, 2006. 